\title{
Een zeer korte videogeschiedenis
}

Het Tijdschrift voor Mediageschiedenis / Journal for Media History heeft sinds haar eerste uitgave in I989, toen nog het Jaarboek Mediageschiedenis, over vele typen media geschreven: televisie, film, radio, digitale media, geschreven pers, amateurfilm en zelfs grafische vormgeving. Video heeft daarentegen niet of nauwelijks aandacht gekregen. Mede daardoor is een lacune ontstaan in een brede historische duiding van een elektronisch medium dat vele toepassingen en verschijningsvormen heeft gekend tijdens haar bestaan in Nederland. Waar het medium aanvankelijk vooral een professionele toepassing vond bij de televisieomroepen van de jaren vijftig en zestig, verankerde het zich geleidelijk ook als medium voor onderwijs en onderzoek, het bedrijfsleven, serieuze amateurs, politiek en sociaal activisten, kunstenaars en niet te vergeten in de vele huiskamers van Nederland. Ondanks deze enorm veelzijdige staat van dienst lijkt video niet te bestaan voor Nederlandse mediahistorici.

Mediafilosofen en -theoretici hebben daarentegen wel aandacht gehad voor video, ware het niet dat al vanaf het prille begin bleek dat 'video' zowel theoretisch als conceptueel een moeilijk te grijpen fenomeen bleek. ${ }^{I}$ Want, zo was de vraag die men zich stelde, wat was video nu eigenlijk? Was het een opname- en opslagmedium bedoeld om live televisie vast te leggen? Moet video dus strikt bezien worden vanuit het perspectief dat het vooral televisie ten dienste heeft gestaan en dus daardoor een integraal onderdeel van de productiegeschiedenis van televisie? Of was het een radicaal nieuwe mediatechnologie waarmee een democratisering kon worden gestimuleerd? Kon met video de invloed van de omroep van onderaf omver worden geworpen? Maar ook: hoe werd video ingezet als een nieuw elektronisch communicatiemiddel voor cultuur, onderwijs en bedrijfsleven? En op welke wijze was het mogelijk video te begrijpen als belangwekkende kunstvorm?

Traditioneel is met name vanuit de kunstgeschiedenis onderzoek gedaan naar video. Kunsthistorici hebben de opkomst van video beschreven als een periode waarin het medium een artistieke bevrijding voor vele jonge kunstenaars betekende. Het experimenteren met en reflecteren op video was onder andere een poging van kunstenaars om het monopolie van televisie als massamedium te verbreken. Maar ook werd video in de jaren zestig, zeventig en tachtig regelmatig ingezet om kunst doelbewust buiten de muren van het museum of de galerie te brengen. Als onderdeel van interactieve en intermediale kunstinstallaties bracht video kunst in toen ongebruikelijke publieke ruimten. ${ }^{2}$ Buiten Nederland is er vooral geschreven over de meer sociaalactivistische gebruikers van video die regelmatig op het snijvlak van kunst en een gehoopte mediademocratisering opereerden. ${ }^{3}$

Met name het thuisgebruik heeft weinig belangstelling gekregen. ${ }^{4}$ De komst van de videorecorder maakte het mogelijk zelf te bepalen wanneer je een televisie-uitzending kon 
bekijken. Maar wat betekende video voor vele Nederlanders wat betreft het zelf onder controle krijgen van het voorheen vluchtige medium televisie?5 ${ }^{5}$ En wat kunnen we zeggen over al die persoonlijke collecties, samengesteld uit een veelvoud van gekoesterde televisieprogramma's en speelfilms opgenomen of aangeschaft op videoband? De rol en opkomst van de videotheek in de jaren tachtig en negentig is eveneens een interessant onderwerp voor nader onderzoek. ${ }^{6}$ De videotheek werd een alledaags instituut voor zowel plezierige, op de familie gerichte, maar soms ook op een illegale, pikante en marginale smaak terende mediaconsumptie. ${ }^{7}$ Daarnaast had de komst van video implicaties voor degenen die ervoor kozen om een camcorder ter hand te nemen om hun alledaagse leven vast te leggen. ${ }^{8}$ Die opnamen staan nu vaak op halfvergane videobanden die hoognodig moeten worden overgezet naar een digitaal format.

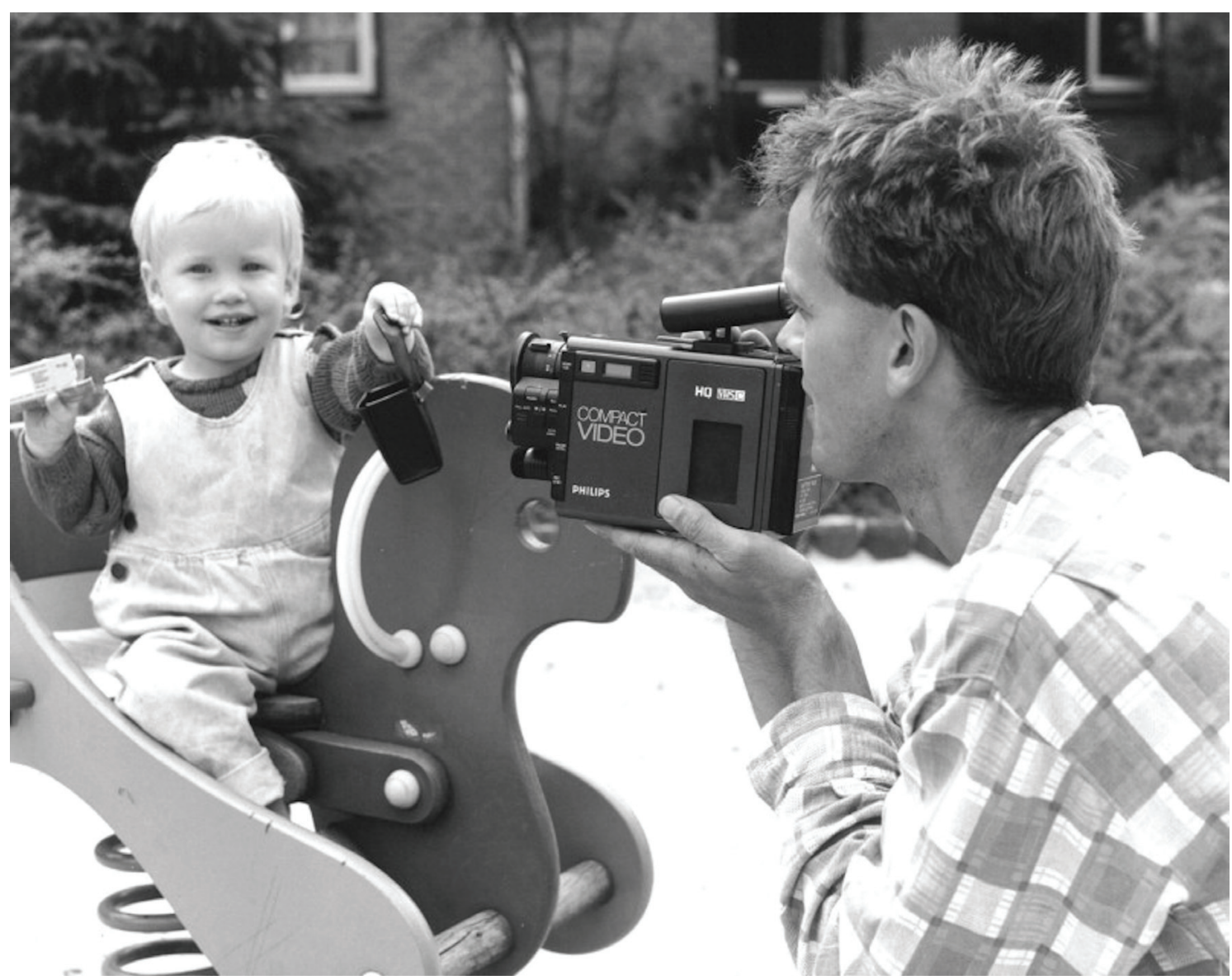

Een vader video-filmt zijn kind met een vroege "compact video" camcorder, 7 augustus 1985. ANP-fotoarchief, gereproduceerd voor niet-commercieel gebruik onder de creative commons licentie.

De vragen en onderwerpen die in deze inleiding worden opgeworpen doen vermoeden dat er nog een flinke slag kan worden geslagen door Nederlandse mediahistorici. Hoewel er dus tot op zekere hoogte een historiografie valt samen te stellen door middel van onderzoek in het buitenland, ontbreekt in Nederland welhaast elk spoor van een serieuze geschiedschrijving. Recent is er een bescheiden begin gemaakt, bijvoorbeeld door mediahistoricus Bert Hogenkamp die in zijn recente boek over de geschiedenis van de documentaire in Nederland ook aandacht schenkt aan de komst van video en hoe op verschillende plekken in Nederland progressieve videogroepen ontstonden. ${ }^{9}$ Ondergetekenden hebben recent in het Europese 
televisiegeschiedenistijdschrift View laten zien hoe een rebelse videocultuur de publieke omroep binnendrong via de VPRO. ${ }^{\text {IO }}$ Het artikel is een onderdeel van een groter onderzoek naar de komst van video dat deel uitmaakte van het NWO-project 'Changing Platforms of Ritualized Memory Practices' waarin op systematische wijze de relatie tussen een nieuwe mediatechnologie en veranderende vormen van amateurgebruik is onderzocht. ${ }^{\text {II }}$

Wat ondertussen duidelijke moge zijn is dat er nog vele vragen zijn te stellen en lacunes te vullen. Reflecterend op de situatie in Nederland lijkt het moeilijk een verklaring te geven voor het grote gebrek aan interesse voor het elektronische medium dat aantoonbaar een wijdverbreid sociaalcultureel maar ook mediahistorisch verschijnsel is geweest in het laatste kwart van de twintigste eeuw. Wellicht is de grote voorliefde onder mediahistorici voor ogenschijnlijk eenvoudig af bakenen media als film, radio en televisie een bepalende factor. Terecht is er lange tijd, met name in het Tijdschrift voor Mediageschiedenis, geijverd om deze en andere massamedia als legitieme historische onderzoeksobjecten geaccepteerd te krijgen, daar waar aanvankelijk argwaan, desinteresse en een voorliefde voor institutionele geschreven bronnen de boventoon voerden onder historici.

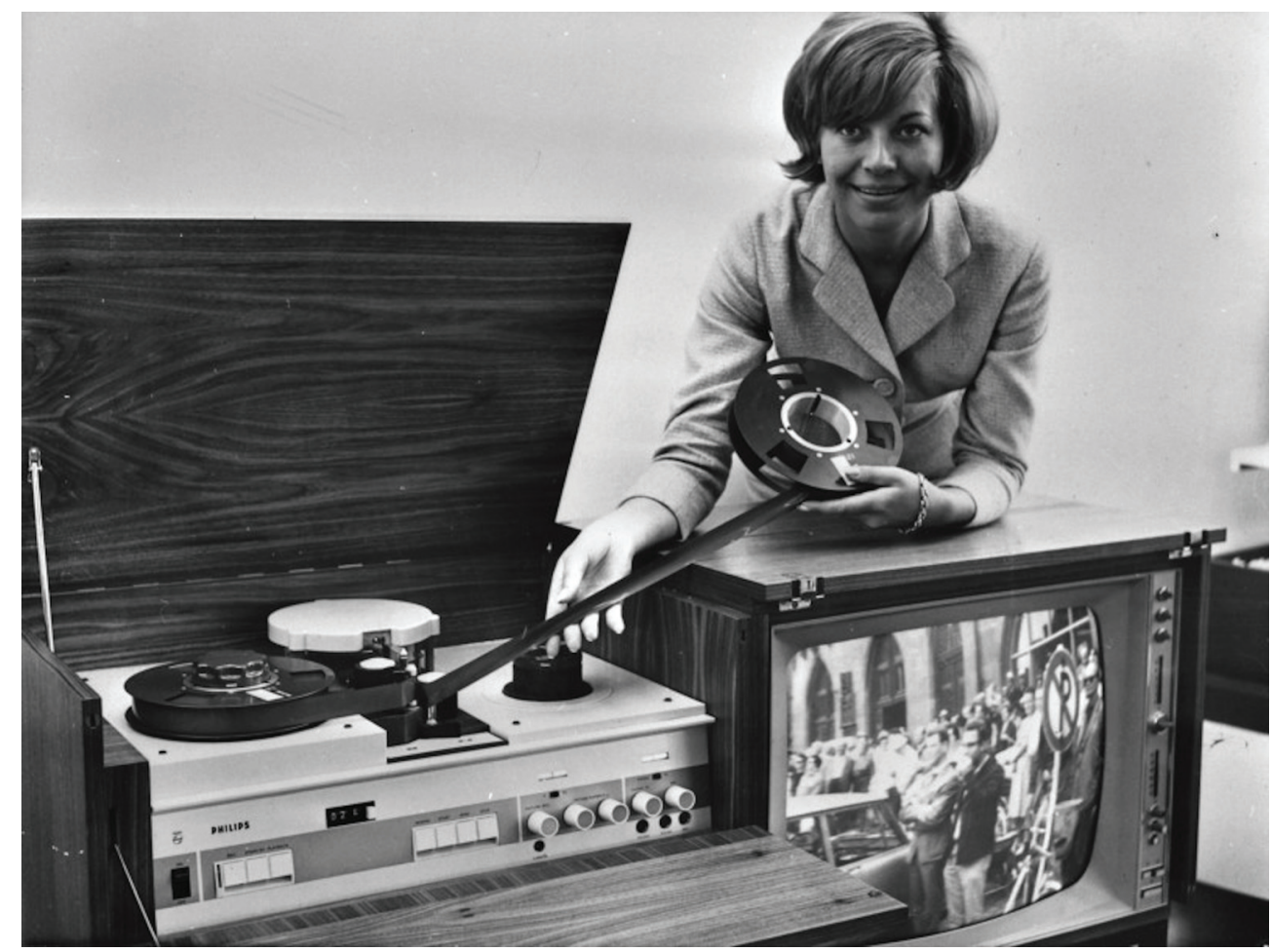

Een vroege Philips open-reel videorecorder gepresenteerd op de Internationale Televisie- en Radiotentoonstelling te Frankfurt, 30 augustus 1965. ANP-fotoarchief, gereproduceerd voor niet-commercieel gebruik onder de creative commons licentie.

Om een klein, bescheiden, beginnetje te maken, biedt TMG een dossier, met als doel om video als historisch medium te agenderen. Het is tijd om terug te kijken en de rijke geschiedenis van video in kaart te brengen. Zo voerde Tom Slootweg voor dit dossier een gesprek met Rien Hagen en Cesar Messemaker, twee oud-leden van het tegendraadse Haagse videocollectief 'Meatball' (I972-I993). Zij wezen er in dat gesprek op dat er een grote argwaan voor video bestond in de professionele filmwereld. 'Er werd in die tijd op video neergekeken door filmers,' aldus Cesar Messemaker, omdat het medium vaak gezien werd als een esthetisch 
inferieur verschijnsel ten opzichte van het alom gerespecteerde mogelijkheden die film bood. Er is een interessante geschiedenis te vertellen over het videocollectief dat video in de jaren zeventig en tachtig op geheel eigen wijze probeerde in te zetten voor sociale, artistieke en democratiserende doeleinden. Het betrof geen obscure groep mensen, maar hun en andere toepassingen van video zijn tot op heden een onderbelicht fenomeen gebleven.

Uit het door ondergetekenden gevoerde gesprek met Gaby Wijers, directeur van de mediakunst instelling LIMA, blijkt opnieuw dat er in Nederland zeker geen desinteresse bestond voor video als belangrijk onderdeel van de moderne kunst. Gedurende vele jaren was de subsidiëring van videokunstprojecten en -instellingen, ondanks vele tegenslagen, toch mogelijk. Er was sprake van een levendige scene in Nederland, vormgegeven en gekenmerkt door zowel buitenlandse als Nederlandse kunstenaars. Dat heeft uiteindelijk geresulteerd in een bijzondere nalatenschap en een niche in de media-erfgoedsector. Hoewel de financiële ondersteuning door de overheid wat betreft deze nalatenschap van de video- en mediakunst in Nederland met de opheffing van het Nederlands Instituut voor Mediakunst (NIMk) ten einde kwam, werd video niet noodzakelijkerwijs als iets ondermaats gezien. Ook heden ten dage blijft LIMA, deels als erfgenaam van het NIMk, een rol spelen in een internationaal netwerk waarin onderzoek, preservatie en distributie voorop staat.

Vervolgens laat mediahistoricus Bert Hogenkamp, gespecialiseerd in de documentairefilm, zien dat hij video niet wil negeren. Zijn in dit dossier opgenomen onderzoek naar videojournaals als communicatiemiddel voor het management in het Nederlandse bedrijfsleven poogt een van de eerder opgeworpen onderwerpen te bestrijken. Het stuk bouwt voort op zijn afscheidsrede in Hilversum waarmee hij zijn Beeld en Geluid leerstoel aan de Vrije Universiteit Amsterdam neerlegde. Hoewel Hogenkamp nu met emeritaat is, hopen wij uiteraard dat zijn constatering ter harte zal worden genomen voor toekomstig onderzoek.

Onderzoek naar de veelzijdige geschiedenis van video in Nederland is van belang. Maar daarvoor moeten wel de juiste voorwaarden aanwezig zijn, zoals bijvoorbeeld collecties rond video in archieven en culturele instellingen. Met andere woorden, waar ligt de videogeschiedenis in Nederland? Veel videoapparatuur, zowel bedoeld voor de professionele als consumentenmarkt, is opgenomen in de apparatencollectie van Beeld en Geluid. De videobanden zelf zijn vaak te vinden in culturele instellingen zoals het LIMA, maar ook ondergebracht in regionale archieven of in lokale beeldbanken. Of ze zijn door hobbyisten zelf gedigitaliseerd en bijvoorbeeld op YouTube geplaatst.

Maar vermoedelijk liggen verreweg de meeste tapes die zijn opgenomen op de zolders, in de kelders of de vele andere opslagplaatsen die Nederland telt. In het ergste geval zijn ze met de komst van digitale media zonder omzien in de vuilniscontainer terechtgekomen, bestempeld als hopeloos verouderde dragers waarvan de bijbehorende afspeelapparatuur defect of verdwenen is. Ook als de analoge tapes gered zijn van een eventuele laatste rustplaats op de vuilnisbelt kan de conservering nog een complexe opgave zijn, zoals blijkt uit de bijdrage van Harry Romijn en René Duursma van het Groninger Audiovisueel Archief (GAVA), onderdeel van RHC Groninger Archieven.

Met dit dossier, bestaande uit interviews en korte bijdragen, hopen we een aanzet te geven om eindelijk de videogeschiedenis te omarmen, door het elektronische medium te zien als een 
die een rijke en veelzijdige sociale, culturele en politieke dimensie kent. Deze aanzet begint uiteraard met archiveren van de bronnen en het toegankelijk maken van collecties. Dit is iets wat zich gelukkig langzaam aan het voltrekken is. Maar er is nog meer te doen, dus laat de bewustwording beginnen...

De collectie Beeld en Geluid (in.beeldengeluid.nl) bevat een uitgebreide fotoverzameling van videorecorders, videocamera's en andere video apparaten die in het depot zijn opgeslagen. De collectie biedt ook toegang tot amateurvideo's die zijn verzameld door het Nederlands Instituut voor Beeld en Geluid. We tonen hier drie voorbeelden uit deze collectie.

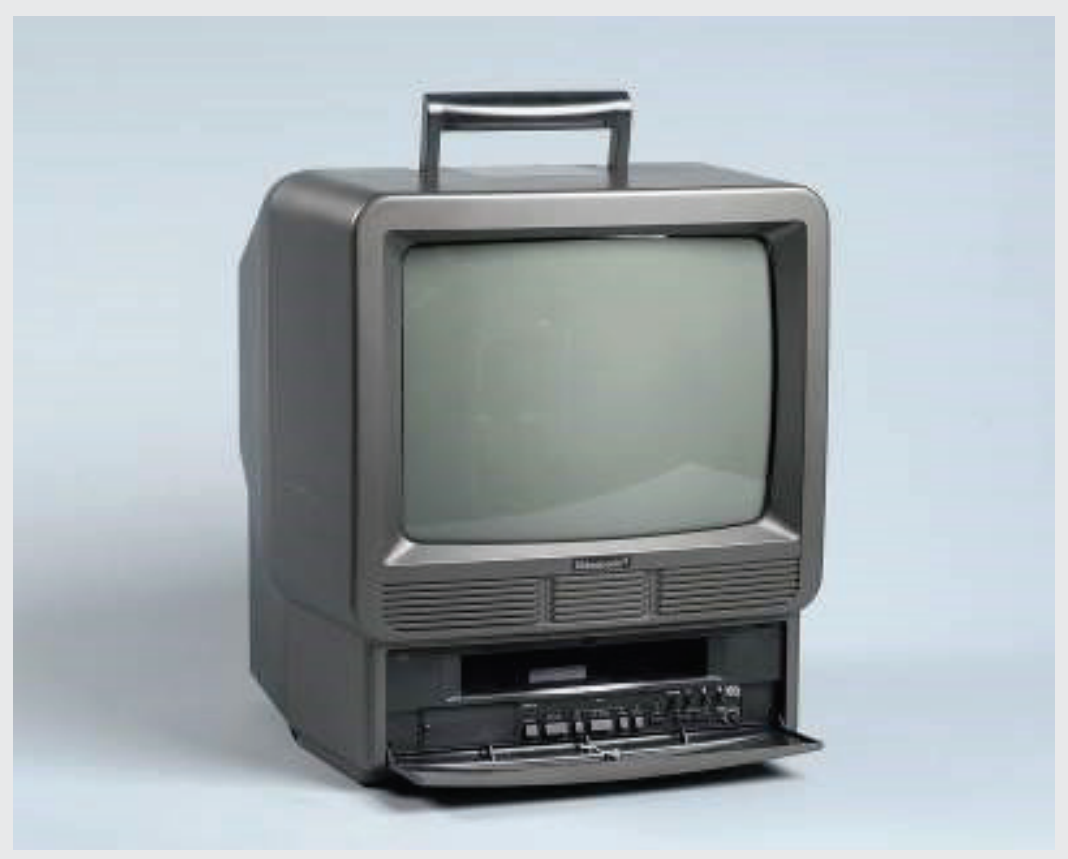

Videotronic VHS 360 POS. VHS-speler in combinatie met monitor, afsluitbaar. Gebruikt in Omroepmuseum 1993-2003.

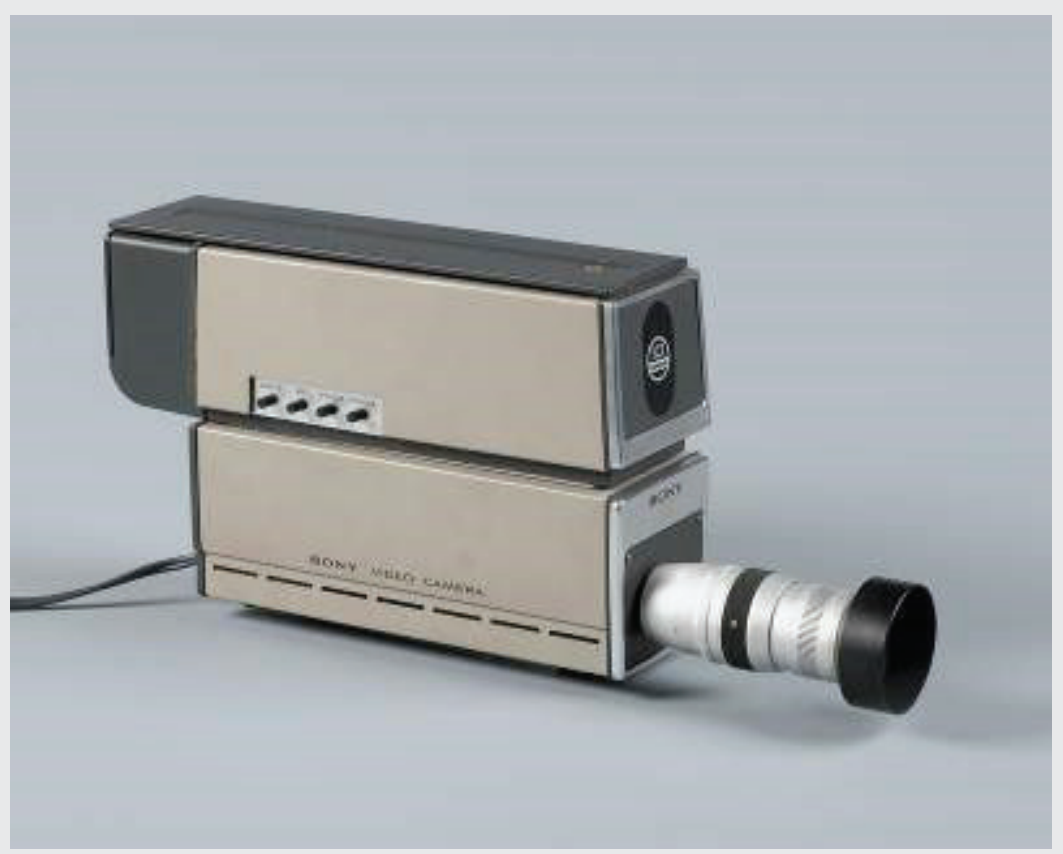

Videorecorder Sony AVC 3200 CE (1970). 


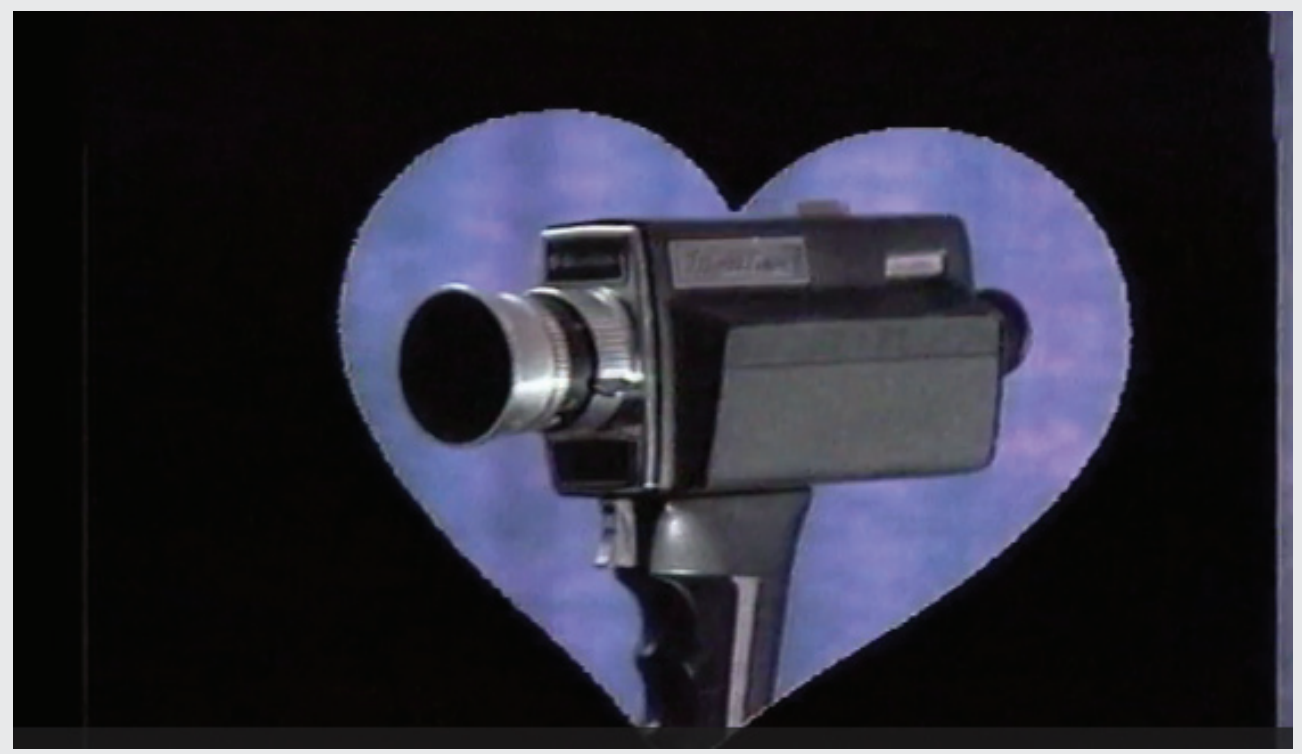

Oh yeah (1 januari 1993). Screen capture uit een videoclip op muziek van Yello gemaakt door de filmclub Heerhugowaard over de komst van het medium video en de dreigende ondergang van Super-8 als medium voor de amateurfilmer.

\section{Noten}

I. Zie bijvoorbeeld het klassieke werk van: Sean Cubitt, Timeshift: On Video Culture (Londen en New York: Routledge, I99I). Zie ook de invloedrijke bundel van: Doug Hall en Sally Jo Fifer, ed., Illuminating Video: An Essential Guide to Video Art (New Jersey: Aperture, I990). Voor een recente theoretische en filosofische her-evaluatie van video, zie: Janna Houwen, Mapping Moving Media: Film and Video (dissertatie, Universiteit Leiden, 20I4).

2. Voor een globale geschiedenis van de internationale videokunstwereld, zie het werk van: Chris Meigh-Andrews, A History of Video Art, Second Edition (Londen en New York: Bloomsbury, 20I4). Voor een Nederlandse geschiedenis van videokunst, zie de bundel van: Jeroen Boomgaard en Bart Rutten, ed., De magnetische tijd: Videokunst in Nederland 1970-1985 (Rotterdam: NAi Uitgevers, 2002).

3. Zie bijvoorbeeld het klassieke onderzoek naar Amerikaanse videocollectieven: Deidre Boyle, Subject to Change: Guerilla Television Revisited (New York en Oxford: Oxford University Press, I997).

4. Zie bijvoorbeeld Michael Newman die de komst en verwachtingen rond video voor thuisgebruik in de Verenigde Staten in kaart heeft gebracht. Michael Z. Newman, Video Revolutions: On the History of a Medium (New York: Columbia University Press, 20I4).

5. De Britse mediatheoreticus en -socioloog Ann Gray bestudeerde ooit het thuisgebruik van video door vrouwen in haar klassieke studie: Ann Gray, Playtime: The Gendering of a Leisure Technology (Londen en New York: Routledge, 1992).

6. Voor een mediageschiedenis van de opkomst van de videotheek in Duitsland zie het werk van: Tobias Haupts, Die Videothek: Zur Geschichte und medialen Praxis einer Kulturellen Institution (Bielefeld: transcript Verlag, 20I4).

7. Voor een onderzoek over de opkomst van legale en illegale home video en de copyright-problematiek in de Angelsaksische wereld, zie Lucas Hildebrand, Inherent Vice: Bootleg Histories of Videotape and Copyright (Durham en Londen: Duke University Press, 2009).

8. Voor een theoretische en conceptuele verkenning van deze amateurpraktijk, zie: James M. Moran, There's No Place Like Home Video (Minneapolis en Londen: Minnesota University Press, 2002). Voor een contemporain onderzoek naar (inclusief ook een historische terugblik op) videogebruik om het alledaagse leven vast te leggen, zie: David Buckingham en Rebekah Willett, Video Cultures: Media Technology and Everyday Creativity (Houndsmill en New York: Palgrave Macmillan, 2009); David Buckingham, Rebekah Willett en Maria Pini, Home Truths? Video Production and Domestic Life (Ann Arbor: The University of Michigan Press en The University of Michigan Library, 20II).

9. Bert Hogenkamp, De Nederlands documentairefilm 1965-1990: De ontwikkeling van een filmgenre in het televisietijdperk (Amsterdam: Boom, 20I5). 
Io. Tom Slootweg en Susan Aasman, "Democratic Television in the Netherlands: Two Curious Cases of Alternative Media as Counter-Technologies," View: Journal of European Television History and Culture, 7 (2015), 2I-37.

II. Naast ondergetekenden bestaat het projectteam uit Andreas Fickers, Jo Wachelder en Tim van der Heiden. Zie voor meer informatie: https://homemoviesproject.wordpress.com/

\section{Biografie}

Susan Aasman is mediahistoricus en werkt als universitair docent Mediastudies en Digital Humanities aan de Rijksuniversiteit Groningen. Haar expertise ligt op het terrein van documentaire en amateurfilm en zij heeft bijdragen geleverd aan tal van artikelen en bundels. Aasman is redactie-voorzitter van het Tijdschrift voor Mediageschiedenis. Tom Slootweg is als promovendus en docent film en media verbonden aan de Rijksuniversiteit Groningen. Voor zijn proefschrift doet hij onderzoek naar de opkomst van video in Nederland en de wijze waarop drie groepen amateurs op verschillende wijze het medium gepercipieerd en gebruikt hebben. Daarnaast is hij recensie-coördinator voor het Tijdschrift voor Mediageschiedenis (TMG-Journal for Media History) en heeft bijdragen geleverd aan View: Journal for European Television History \& Culture en de bundel Exposing the Film Apparatus: The Film Archive as Research Laboratory (Amsterdam University Press, 20I6) onder redactie van Giovanna Fossati en Annie van den Oever. 